\title{
Enfermedad de Kikuchi. Una posibilidad diagnóstica ante la presencia de adenopatías cervicales
}

\author{
J.M. Valero Recio, A. Álvarez Urda, L. Gil Sánchez, J. Morera Montes* \\ Residente de Tercer Año de Mediana Familiar y Comunitaria. \\ * Especialista en Mediana Familiar y Comunitaria. \\ Centro de Salud "V Centenario". San Sebastián de los Reyes. Área 5. Madrid.
}

\section{RESUMEN}

La enfermedad de Kikuchi, o linfadenitis necro tizante histiocitaria, es una entidad que se mani fiesta con adenopatías cervicales y cursa de forma benigna, y que aunque infrecuente fuera de Asia, también se puede presentar en nuestro medio, por lo que deberemos tenerla en cuenta ante un cuadro de adenopatía cervical. Puede asociarse fundamentalmente a infecciones virales, incluido el VIH, y trastornos autoinmunes. Presentamos el caso de un varón joven que fue diagnosticado en nuestro centro de salud de esta enfermedad.

Palabras clave: Linfadenitis. Linfadenitis histio citaria necrotizante. Atención Primaria de Salud.
Kikuchi's disease. A diagnostic possibility of cer vical lymphadenopathy

\section{ABSTRACT}

Kikuchi's disease (histiocytic necrotizing lym phadenitis) is an entity which is manifested by cer vical lymphadenopathy and has a benign course. Although it is rare outside Asia, it can also be seen in the western world, therefore it must be discarded when faced with a patient presenting cervical ade nopathy. It's associated mainly with viral infec tions, including HIV, and autoimmune disease. We present the case of a young man diagnosed of this disease in our Primary Health Care center.

Key words: Lymphadenitis. Histiocytic necroti zing lymphadenitis. Primary Health Care.

\section{INTRODUCCIÓN}

Las adenopatías son un motivo de consulta frecuente en Atención Primaria, que obliga a plantearse diferentes diagnósticos diferenciales de gravedad muy diversa. Entre estos procesos, uno infrecuente pero que hay que tener presente, es la enfermedad de Kikuchi.

\section{CASO CLÍNICO}

Presentamos el caso de un varón de 29 años que consultó por fiebre de $38^{\circ}$ de 48 horas de evolución, tos escasa y expectoración blanquecina. En la exploración sólo se apreció hipertrofia en amígdala izquierda con adenopatías en cadena yugular izquierda de gran tamaño $(3 \times 3 \mathrm{~cm})$. Ante la sospe- cha de faringoamigdalitis bacteriana se pautó tratamiento con amoxicilina e ibuprofeno. No obstante, ante el tamaño de las adenopatías se decide solicitar test de mononucleosis infecciosa (MI) y analítica general.

Acude de nuevo a los 14 días por fiebre alta, malestar general, cansancio intenso y dolor en región laterocervical izquierda. En este momento en la exploración se aprecia gran adenopatía submaxilar izquierda de $3 \times 2 \mathrm{~cm}$ dolorosa a la palpación y otra supraclavicular izquierda. No se observan adenopatías en otros grupos ganglionares, hepatoesplenomegalia, lesiones cutáneas o afectación articular. No se aprecian lesiones locales, la otoscopia es normal, la exploración faríngea y tiroidea son normales. En la analítica destaca: LDH 1400 UI/l, GOT 56, GPT 47 UI/l, no existe leucocitosis, sólo 
una leve linfocitosis. Test de MI: negativo. Se solicita test para el virus de la inmunodeficiencia humana (VIH), análisis anatomopatológico mediante punción aspiración con aguja fina (PAAF) y de nuevo test de MI. Para evitar demoras el paciente acude a un centro privado para la realización de PAAF y los cirujanos encargados de realizarla, ante el tamaño de las adenopatías, deciden la realización de biopsia. El resultado del test de MI es nuevamente negativo.

La evolución fue favorable, persistiendo febrícula durante 20 días y con disminución lenta y paulatina del tamaño de las adenopatías.

El resultado de la biopsia se informa como: linfadenitis histiocitaria necrotizante o enfermedad de Kikuchi. Ante este resultado se solicita una nueva analítica y otras pruebas complementarias para descartar posibles procesos asociados a esta enfermedad.

Los resultados son los siguientes: factor reumatoide negativo, anticuerpos antinucleares (ANAs) negativos, ecografía abdominal normal.

\section{DISCUSIÓN}

La linfadenitis necrotizante histiocitaria fue descrita por primera vez en 1972, por Kikuchi e independientemente por Fujimoto et al. en Japón; también se denomina linfadenitis necrotizante subaguda o enfermedad de Kikuchi-Fujimoto (EKF).

Es más frecuente en asiáticos, aunque están aumentando los casos en el resto del mundo ${ }^{1}$ y en mujeres (proporción varón / mujer 1:4). La edad de presentación son los 30 años de media. Se ha visto asociación con antígenos HLA de clase II DPB1 0202 y DPA1 01² (más habitual en población con EKF que en sanos), que son más frecuentes en la población asiática que la caucasiana.

Se presentan más frecuentemente como adenopatías cervicales (aunque también pueden ser generalizadas $^{1}$ ), en general múltiples y algo dolorosas con / sin fiebre, a veces sudoración, escalofríos, dolor de garganta, manifestaciones cutáneas en un $30 \% 3$ (que suelen asemejar exantemas rubeólicos, medicamentosos, los asociados a linfomas o al lupus eritematoso subagudo), artralgias, mialgias, malestar general, pérdida de peso, y cefalea, náuseas y vómitos. En la exploración además de las adenopatías y las manifestaciones cutáneas también puede haber esplenomegalia. Se ha visto una asociación con meningitis aguda aséptica, generalmente antes de la aparición de la linfadenitis ${ }^{4}$.

En las pruebas complementarias se puede encontrar leucopenia, linfocitosis, elevación de transaminasas y de LDH, a veces elevación de la velocidad de sedimentación globular (VSG), proteína $\mathrm{C}$ reactiva $(\mathrm{PCR})^{5}$ y presencia de linfocitos atípicos en sangre periférica.

En casi todos los casos la evolución es benigna y se produce la curación de 1 a 3 meses. Las recurrencias son infrecuentes (alrededor de un 3\%), aunque ha habido casos de recurrencias de hasta 12-18 años después del primer episodio ${ }^{6}$. Las muertes por la enfermedad de EKF son excepcionales.

Se han visto casos asociados a la enfermedad de $\mathrm{Still}^{3}$, al lupus eritematoso sistémico (LES), a esclerodermia $^{7}$, a $\mathrm{VIH}^{8}$ y a otras enfermedades infecciosas y autoinmunes.

Las lesiones más típicas en ganglios linfáticos son: lesiones paracorticales compuestas de necrosis fibrinoide eosinofílica con restos cariorrécticos rodeadas de un infiltrado de macrófagos con restos fagocíticos, histiocitos espumosos, monocitos plasmacitoides, inmunoblastos $\mathrm{T}$ y células mononucleares atípicas con núcleos arremolinados. Cuando existe afectación cutánea, un infiltrado similar se ve en dermis e hipodermis ${ }^{3}$. A diferencia de otras enfermedades, característicamente no hay granulocitos, granulomas, células gigantes multinucleadas ni células plasmáticas.

A veces se ve, previa a la fase necrotizante, una fase proliferativa, donde predominan las células mononucleares atípicas, incluyendo los inmunoblastos. También se puede ver una fase postnecrotizante (xantomatosa), donde predominan los histiocitos espumosos.

Aunque se ha publicado que las citologías por PAAF pueden ser diagnósticas ${ }^{1}$, muchas veces son insuficientes ${ }^{1}$, ya que pueden ser muy parecidas a linfomas (sobre todo debido a la presencia de inmunoblastos), por lo que se necesita biopsia para diferenciar bien la histología. Esto es especialmente importante en casos de adenopatías en la infección por VIH, ya que la importancia de diferenciar linfomas y casos de EKF asociados al virus es grande $^{8}$. Se ha dado el caso de pacientes que recibieron quimioterapia por un error diagnóstico de este tipo ${ }^{1}$. Hay que resaltar que no hay asociación clínica entre linfomas y EKF.

Las características anatomopatológicas son con frecuencia muy parecidas a las que se ven en linfadenitis por LES, tuberculosis 9 , y otras enfermedades infecciosas y autoinmunes.

Varias características de EKF sugieren que la etiología puede ser infecciosa o autoinmune, como son las manifestaciones de linfadenitis, fiebre, escalofríos, exantema, artralgias y mialgias.

Imamura et al. sugirió que EKF podría ser una respuesta hiperinmune a una infección por virus linfocitotrópicos (esto podría explicar las etiologías de EKF, enfermedad de Still y LES). Las características histológicas de EKF a veces son muy difíciles de diferenciar de linfadenitis asociada a LES, y han sido descritos varios casos de EKF asociados a LES.

Las manifestaciones clínicas e histológicas de EKF asemejan las de una infección subaguda. El curso benigno y la recuperación completa asemejan 
más una infección que un proceso autoinmune como el LES. Los cambios histológicos deben de ser diferenciados de las linfadenitis por Toxoplasma gondii, Yersinia enterocolítica, Bartonella henselae, por el virus de Ebstein Barr (VEB), virus herpes 8 (HHV-8), HIV-1 y Parvovirus ${ }^{10}$. Muchas características de EKF también son similares al síndrome hemofagocítico asociado al VEB.

Las elevaciones serológicas no han sido muy concluyentes a la hora de establecer una relación etiopatogénica.Usando técnicas de PCR e hibridización in situ (HIS) se ha encontrado ADN de HHV- 8 en el $23 \%$ de casos de EKF, mientras que se encontraron $0 \%$ en tejido reactivo. El agente infeccioso más encontrado en asociación con EKF es $\mathrm{VEB}$, aunque no se ha podido establecer una relación causal.

Usando pruebas conjuntas de hibridización in si tu (HIS) de RNA de VEB, se ha visto que el número de linfocitos que contienen material RNA de VEB es máximo en la fase proliferativa y va disminuyendo al mismo tiempo que el número de histiocitos que contienen células fagocitadas con RNA de VEB aumenta. Esto, junto con el contexto de la respuesta inmune intensa que caracteriza a EKF, sugiere que el $\mathrm{VEB}^{5,11}$ podría estimular una respuesta autoinmune por medio de linfocitos $\mathrm{T}$ citotóxicos (dado que las biopsias se realizan en un estadio necrotizante de la enfermedad pocas veces se ven cantidades significativas de linfocitos con ma- terial ADN de VEB), que luego experimentarían apoptosis (probablemente en lugar de necrosis ${ }^{5}$ ), para posteriormente ser fagocitadas por los histiocitos.

Se ha realizado tratamiento en algunos casos con prednisolona $30 \mathrm{mg} /$ día en dosis decreciente durante 50 días, mejorando los síntomas. Los antibióticos son totalmente inefectivos.

El diagnóstico diferencial se debe hacer en especial con las enfermedades que causan adenopatías cervicales, es decir, faringoamigdalitis, infecciones virales (p. ej., mononucleosis infecciosa, VIH), enfermedad de Kawasaki, enfermedad por arañazo de gato, tuberculosis, toxoplasmosis, linfomas, sarcoidosis y LES.

Puede que haya casos no diagnosticados de alteración cutánea, si no se hace histología de los ganglios ni de la piel, ya que la alteración cutánea es bastante inespecífica y puede imitar múltiples cuadros autoinmunes o infecciosos.

\section{CORRESPONDENCIA:}

José Manuel Valero Recio

Carretera Antigua de La Coruña, 29, 1. ${ }^{\circ} \mathrm{D}$

28400 Collado Villalba. Madrid

\section{Bibliografía}

1. Jayaraj SM, Lloyd J, Frosh AC, Patel KS. Kikuchi-Fujimoto's syndrome masquerading as tuberculosis. J Laryngol Otol 1998; 112 (9): 898-900.

2. Tanaka T, Ohmori M, Yasunaga S, Ohshima K, Kikuchi M, Sasazuki T. DNA typing of HLA class II genes (HLA-DR, DQ and -DP) in Japanese patients with histiocytic necrotizing lymphadenitis (Kikuchi's disease). Tissue Antigens 1999; 54 (3): 246-53

3. Cousin F, Grezard P, Roth B, Balme B, Gregoire-Bardel M, Perrot H. Kikuchi disease associated with Still disease. Int J Dermatol 1999; 38 (6): 464-7.

4. Sato Y, Kuno H, Oizumi K. Histiocytic necrotizing lymphadenitis (Kikuchi's disease) with aseptic meningitis. J Neurol Sci 1999 1;163 (2): 187-91

5. Ura H, Yamada N, Torii H, Imakado S, Iozumi K, Shimada S. Histiocytic necrotizing lymphadenitis (Kikuchi's disease): the necrotic appearance of the lymph node cells is caused by apoptosis. J Dermatol 1999; 26 (6): 385-9.
6. Blewitt RW, Kumar SN, Abraham JS. Recurrence of Kikuchi's lymphadenitis after 12 years. J Clin Pathol 2000; 53 (2): 157-8.

7. Laeng RH, Stamm B. Kikuchi's histiocytic necrotizing lymphadenitis driven by activated cytolytic T-cells: an example associated with systemic scleroderma. Histopathology 1999; 34 (4): 373-4.

8. Ereno C. Kikuchi lymphadenitis and AIDS. Histopathology 1999; 34 (3): 273.

9. Yoo JH, Choi JH, Kim YR, Shin WS, Kang MW. KikuchiFujimoto disease: benign cause of fever and lymphadenopathy. Am J Med 1997; 103 (4): 332-4.

10. Yufu Y, Matsumoto M, Miyamura T, Nishimura J, Nawata H, Ohshima K. Parvovirus B19-associated haemophagocytic syndrome with lymphadenopathy resembling histiocytic necrotizing lymphadenitis Kikuchi's disease). Br J Haematol 1997; 96 (4): 868-71.

11. Hudnall SD. Kikuchi-Fujimoto disease. Is Epstein-Barr virus the culprit? Am J Clin Pathol 2000; 113 (6): 761-4. 